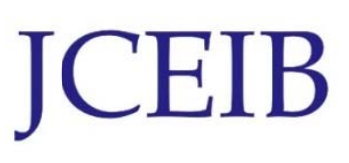

Journal Chemical Engineering and Industrial Biotechnology (JCEIB)

ISSN: 0126-8139 (Online); Open Access

Volume 5Issue 5 pp. 57-73; May 2019

OUniversiti Malaysia Pahang Publisher

DOI: https://doi.org/10.15282/JCEIB-V5-06.29/3/2019/5.5

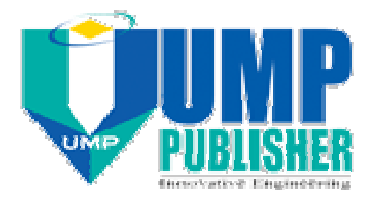

\title{
ETHNO-MEDICINAL POTENTIALS AND PHYTOCHEMICAL PROPERTIES OF Aloe vera: A REVIEW
}

\author{
John Adewole Alara ${ }^{a^{*}}$, Oluwaseun Ruth Alara ${ }^{\mathrm{b}}$ \\ ${ }^{a}$ Primary Health Centre (PHC), Surulere Local Government, 210, Iresa-Adu, Oyo State, Nigeria \\ ${ }^{b}$ Faculty of Chemical \& Natural Resources Engineering, Universiti Malaysia Pahang, 26300 Gambang, \\ Pahang, Malaysia \\ *Corresponding author:alaraadeseun@gmail.com \\ Tel: +2348073305176
}

\begin{abstract}
Aloe vera is a perennial ethno-medicinal potential plant with a xerophytic characteristic, but not a cactus. It has a famous history owing to its phytopharmaceutical properties and this had made it useful in the pharmaceutical, cosmetic and food industries. Studies had shown the positive effects of its extract against bacteria, fungi, virus and parasitic organisms. The phytochemical properties of $A$. vera have been exploited for various economic and commercial purposes. This review contributes literature on the bioactive potential composition, processing and the pharmaceutical potential uses, an adverse side-effect that might spring up in case of over dosage and important safety precautions are summarized. More scientific innovations and developments in the aspect of analytical chemistry are on the way to provide more acceptable, purified chemical characterization of $A$. vera using sophisticated laboratory equipment and machines.
\end{abstract}

Keywords: Aloe vera; Pharmacological properties; Composition; Phytochemical

\subsection{INTRODUCTION}

Aloe vera as an ethno-medicinal plant is in high esteem position in the pharmacological set up due to the presence of richly bioactive components it possesses which are of medicinal value as established by the World Health Organization (WHO). Their affirmation was that about $80 \%$ of the global population solemnly relied on the ancestral medicines for their recovery while the remaining $20 \%$ of the global population only resides in advanced countries of the world (Raksha, 2014). However, there is an increase in demand for $A$. vera through out the world because it is a natural product that has no adverse side-effects, non-narcotic, economically affordable, biodegradable and ecology friendly (Maan et al., 2018). Phytochemicals present in medicinal plants are used for new drugs design and discovery. It has its origin from the tropical South and East Africa as well as the Mediterranean areas. There are over 400 species found all over the world and it is cultivated mostly in the subtropical regions. It is a perennial plant with shrubby and succulent green leaves usually varies from bright green to grey colour in a rosette pattern at the plant stem. The flesh of the leaves is triangular with serrated edges made up of a thick epidermis called mesophyll which are enveloped by the cuticle. During the drought long period or warm dry climate condition, the leaves 
have great ability to store water in order to survive the harsh condition (Lanka, 2018; Maan et al., 2018; Pansar et al., 2018; Sahu et al., 2013).

However, A. vera belongs to the members of the tree lily family called Alliaceaebut it is not cactus. Other members of the lily family that are related to this plant are garlic, onion and turnip families. The relationship of this plant with the lily family is a manifestation of tubular yellow flowers that came out during the spring period annually which also has the same resemblance with those of the Easter lily. However, A. vera as a medicinal plant has been used in past time for their therapeutic reasons. Its common names are Zanzibar aloe, Aloe spicata, Barbados aloe, Chirukattali (India), Laloi (Haiti), Kumari (Sanskrit), Luhu (Chinese), Sabilla (Cuba), Nohwa (Korean), Subr(Arabic), Aloe, Cape aloe (South Africa), Ghikumar (India), Ghai Kunwar (India), Aloe vera, Socotrine aloe, Lohoi (Vietnam), Curacao aloe, Rokai (Japanese), and Indian aloes (Raksha, 2014). These plants cannot survive in the cold region; when they are cultivated, matured one can grow to reach 2.5 to 48 in height and 28 to 36 in diameter. Each Aloe plant usually has about 12 to 16 leaves, weighing up to 3 pounds. Every 6 to 8 weeks, the plants can be harvested with about 3 to 4 leaves in each plant is removed.

Furthermore, A. vera among other species is regarded as the most populous, commercialised and potential plant in the field of study. Different parts of A. vera contain about 200 active compounds such as vitamins, saponins, sugar, amino acids, minerals, lignins, salicylic acid, anthrapequinonones, and enzymes as well as 75 nutrients (Misir et al., 2014). The flowers contain ascorbic acid and volatile compounds while the rind contains lignin, polysaccharide, pectin, cellulose, and hemicellulose (Maan et al., 2018). Likewise, the leaves serve as a source of different enzymes, vitamins, minerals, organic acids, and phenolic compounds (Maan et al., 2018; RahimiDehgolan et al., 2012).

However, this plant is distinguished for its antidiabetic, antioxidant, immune boost, anticancer, sunburn relief, anti-ageing, and anti-inflammatory activities (Langmead et al., 2004). Recently, A. vera has become more popular due to its herbal movement established by yoguru, holistic healers, alternative medicine promoters, and naturopaths. The industrial size of aloe raw product has been evaluated to be around $\$ 125$ million dollars and the volume of finished aloe product for the industry is about $\$ 110$ billion dollars (Pandey \& Singh, 2016). The presence of these unique compounds has initiated different industrial applications of Aloe vera. Therefore, this review summarises the medical potential, phytochemical properties with their mechanism of action of Aloe vera, and industrial applications.

\subsection{BOTANICAL DESCRIPTION}

A. vera resembles xerophyte with a spiky cactus (Figure 1). It is a perennial clumpforming plant with a strong fibrous root, it produces about 12 to 16 basal leaves per plant weighing around $1500 \mathrm{~g}$ when it matures. When the plant is around 4 years old, it becomes matured; it has 12 years as its life span. The length of the leaves is about $0.5 \mathrm{~m}$ long and 8 to $10 \mathrm{~cm}$ breadth with a saw-like tooth across its margins. If the leave is in a transverse section, it will show a slight concave image on the adaxial surface while the convex image will show on a low abaxial surface. The plant flowers stalk grew to about $1.5 \mathrm{~m}$ in height while the fruits contain many seeds in a triangular capsule shape (Sahu et al., 2013). A. vera is practically free from infections, but sometimes black spot may 
appear on the plant due to fungal disease, and this may destroy the entire plant. Soft rotting is usually caused by bacterial infection and $A$. vera enemy is frost because it cannot survive in frost states. Most of the A. vera is not toxic, but few contain hemlock like poisonous substance (Sahu et al., 2013).

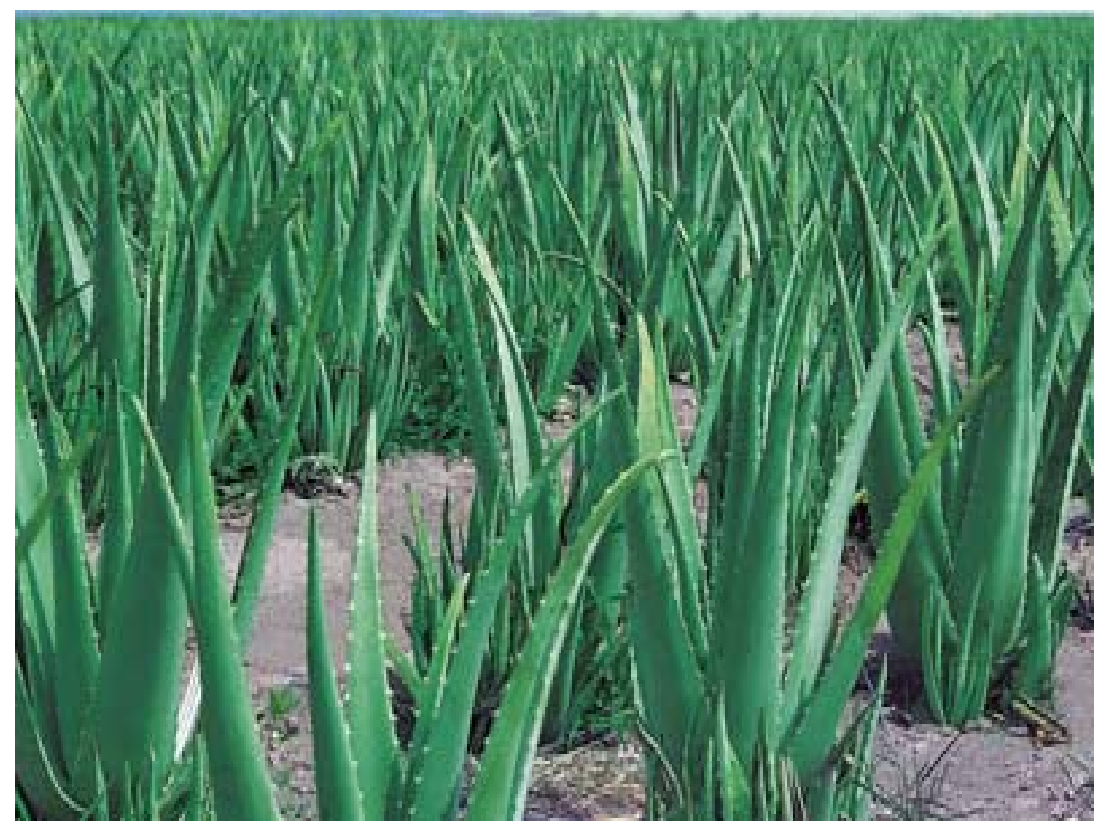

Figure 1. Aloe vera

\subsection{CULTIVATION AND PROPAGATION}

Inadequate production of $A$. vera to meet the increased demand by both cosmetic and pharmaceutical industries has been revealed in the previous studies (Ahlawat and Khatkar, 2011). Using sucker as a means of natural propagation of axillary shoots of $A$. vera is a slow multiplication way of meeting the growing demand. Likewise, the recent production of leaves is not good enough to meet the increasing demand of this plant for industrial usage. Moreover, the seed for sexual propagation of $A$. vera has a barrier because of the presence of male sterility. Another factor is that the less production of lateral shoot annually for vegetative propagation from a single donor is not encouraging. However, employing the use of standardized micropropagation methods become the better solution to solve these challenges of low production of A. vera for industrial purposes (Maan et al., 2018; Molsaghi et al., 2014; Raksha, 2014; Zakia et al., 2013).

\subsection{PHYTOCHEMISTRY OF ALOE VERA}

The physical chemistry of bioactive compounds in $A$. vera has been identified for many years till date using various techniques including micellar electrokinetic chromatography, capillary electrophoresis, counter current chromatography, HPLC, GC/MS, GC, LC/MS, LC-ESI-MS/MS, atomic absorption spectrometry, size exclusion chromatography, thin layer chromatography, and fluoro-photometry (Arunkumar \& Muthuselvam (2009); Mukherjee et al., 2013). Arunkumar and Muthuselvam (2009) used GC-MS and qualitative method to identify about 26 bioactive compounds from the ethanolic extract of $A$. vera. The $A$. vera gel is made up of the following: $55 \%$ of polysaccharides, $16 \%$ of minerals, $17 \%$ of sugars, $1 \%$ phenolic compounds, $4 \%$ of lipid, $0.66 \%$ of solid content, and $0.56 \%$ of soluble solid (Pandey \& Singh, 2016). The leaf of 
A. vera is made up of $98 \%$ of water. It is made up a lot of important antioxidant and vitamins such as vitamin A, thiamine (vitamin B1), riboflavin (vitamin B2), niacin, folic acid, choline, vitamin C, and E (Pandey and Singh, 2016). Furthermore, the leaves of most species contain phenolic compounds which have analysed chromatographically. The results showed more than 100 major zones, characterised with a stained colour of different dyes which were identified and characterized as anthraquinone and chromone and other bioactive compounds such as salicylic acid, lactate, magnesium, and bradykininase (Mukherjee et al., 2013). Table 1 illustrates the different important bioactive compounds identified in A. vera.

Table 1: Bioactive compounds in Aloe vera

\begin{tabular}{|c|c|c|c|c|}
\hline No & $\begin{array}{l}\text { Phytochemical } \\
\text { group }\end{array}$ & Bioactive compounds & $\begin{array}{l}\text { Medicinal properties } \\
\text { and activity }\end{array}$ & References \\
\hline 1 & $\begin{array}{l}\text { Anthrones/ } \\
\text { anthraquinone }\end{array}$ & $\begin{array}{l}\text { Aloin A and B (barbaloin), } \\
\text { aloetic-acid, aloe-emodin, } \\
\text { emodin, ester of cinnemonic } \\
\text { acid, resistannol, chrysophanic } \\
\text { acid, ethereal oil, isobarbaloin, } \\
\text { anthranon, and anthracine }\end{array}$ & $\begin{array}{l}\text { Antibacterial, } \\
\text { antiviral and } \\
\text { analgesic agent }\end{array}$ & $\begin{array}{l}\text { Maan et al. } \\
(2018) ; \\
\text { Mukherjee et al. } \\
\text { (2013); Sandeep } \\
\text { and } \quad \text { Yadav } \\
\text { (2014); }\end{array}$ \\
\hline 2 & Chromones & $\begin{array}{l}\text { 8-C-glucosyl-(8)-aloesol, 8-C- } \\
\text { glucosyl-(2'-O-cinnamonyl)-7- } \\
\text { O-methylaloediol A, 8-C- } \\
\text { glucosyl-noreugenin, neoalosin } \\
\text { A, 8-C-glucosyl- (S)- aloesol, } \\
\text { and isorbaichromone }\end{array}$ & $\begin{array}{l}\text { Anti-inflammatory } \\
\text { agent }\end{array}$ & $\begin{array}{l}\text { Maan et al., 2018; } \\
\text { Mukherjee et al. } \\
\text { (2013); Sandeep } \\
\text { and Yadav } \\
\text { (2014); Liu et al. } \\
\text { (2013) }\end{array}$ \\
\hline 3 & Enzymes & $\begin{array}{l}\begin{array}{l}\text { cyclooxygenase, } \\
\text { cyclooxidase, }\end{array} \\
\text { peroxidase, catalase, } \\
\text { dismutase, cellulase, alkaline } \\
\text { phosphatase, } \\
\text { carboxypeptidase, } \\
\text { phosphoenolpyruvate, } \\
\text { carboxylase, and lipase }\end{array}$ & $\begin{array}{l}\text { Antiviral } \\
\text { antifungal agent }\end{array}$ & $\begin{array}{l}\text { Choche et al. } \\
(2014) ; \quad \text { Lanka } \\
(2018)\end{array}$ \\
\hline 4 & Carbohydrates & $\begin{array}{l}\text { Sugars such as fucose, glucose, } \\
\text { mannose, cellulose, fructose, } \\
\text { arabinose, galactose, lactose, } \\
\text { fructose, xylose, sucrose } \\
\text { rhamnose, uronic acids, } \\
\text { maltose, pectic substance, and } \\
\text { lignins }\end{array}$ & $\begin{array}{l}\text { Anti-allergic, } \\
\text { inflammatory } \\
\text { anti-viral }\end{array}$ & $\begin{array}{l}\text { Maan et al. } \\
\text { (2018); } \\
\text { Mukherjee et al. } \\
\text { (2013); Sandeep } \\
\text { \& Yadav (2014) }\end{array}$ \\
\hline 5 & Minerals & $\begin{array}{l}\text { Zinc, phosphorous, chlorine, } \\
\text { copper, iron, manganese, } \\
\text { chromium, calcium, sodium, } \\
\text { magnesium, and potassium }\end{array}$ & Antioxidant & $\begin{array}{l}\text { Sandeep \& Yadav } \\
\text { (2014); Liu et al. } \\
\text { (2013); Maan et } \\
\text { al. (2018); } \\
\text { Mukherjee et al. } \\
\text { (2013); Sahu et } \\
\text { al. (2013) }\end{array}$ \\
\hline 6 & Vitamins & $\begin{array}{l}\text { Choline and vitamin (A, B, B1, } \\
\text { B2, B 6, B 9, C, and E) }\end{array}$ & Antioxidant & $\begin{array}{lr}\text { Lanka (2018); } \\
\text { Maan et al. } \\
(2018)\end{array}$ \\
\hline
\end{tabular}


$7 \quad$ Amino acids

8

Organic acids

Lipids organic compounds

10 Proteins
Arginine, alanine, aspartic acid, glutamic acid, cysteine, glycine, hydroxyproline, histidine, proline, leucine, serine, lysine, methionine, valine, isoleucine, threonine, phenylalanine, and tyrosine

Citric acid, fumaric acid, formic acid, acetic acid, lactic acid, tartaric acid, pyruvate, succinic acid, and malic acid

\author{
Anti-inflammatory, Maan et al. \\ antibacterial and (2018); Ombito et \\ analgesic al. (2015)
}

$\begin{array}{ll}\text { Anti-inflammatory } & \text { Maan } \\ \text { agent and antiseptic } & \text { (2018); }\end{array}$ Mukherjee et al. (2013); Sahu et al. (2013);

Sandeep \& Yadav (2014)

Antiseptic, anti- Maan et al. inflammatory and (2018) analgesic agent

Anti-inflammatory, Maan et al. antibacterial and (2018); Sahu et analgesic al. (2013);

Sandeep \& Yadav (2014)

\subsection{HOW TO PROCESS Aloe vera}

A. vera had served as a constituent in various formulations. This plant needs enough of suitable processes and various preparations of different products accordingly. The use of $A$. vera as a constituent is the composition that increases the real ingredient while they are still inactive condition without changing their form to reduce the constituent in a negative form and to produce a needed result as a finished product with a preferable benefit (Eshun \& He, 2004). Various processing procedures can be accompanied based on the essential demand of the industry with differences in quality product. Generally, A. vera can be produced into a different form such as a concentrate, powder and juice (Eshun and He, 2004; Maan et al., 2018).

\subsection{A. vera Juice}

Traditionally, A. vera juice is prepared by detaching and washing the leaf margin that are unpleasant parts. Under a refrigerated temperature of $4{ }^{\circ} \mathrm{C}$, the juices are extracted by adding the materials to the pulpier. Then, the extracted juice can be stored at a lower temperature in order to avoid depletion of sensitive bioactive molecules (Maan et al., 2018). Another method that can be used in preparing the juice is by removing the tip and base of the leaf, grind to make a slurry in form of soup consistency and then, treat with cellulose enzyme to free the constituents in the cell. Later, the material can be placed inside various course filters to filter-out the impurities such as rind particles. The liquid that is produced at the cause of the grinding process may be due to the de-pulping of the large piece of pulp that is formed. Finally, the material can be filtered using filters to eliminate traces of sand, leaves, emodin, aloin, and any particles. The bioactive constituents in the juice were three times compared to the traditional technique using this method (Ramachandra \& Srinivasa Rao, 2008). 


\subsection{A. vera Powder}

The $A$. vera powder is being produced by washing the $A$. vera fillets, put it inside a humidity chamber under suitable temperature and use hot air to dry the fillets (Ahlawat and Khatkar, 2011). Then, grind the dried materials and packed. However, the sensitive bioactive compounds of $A$. vera can be destroyed using the traditional drying method because it is detrimental to the temperature-sensitive bioactive compounds in the $A$. vera. Although, this process consumed time and not economical. Alternatively, a microwave-assisted drying method is a novel improved effective method that has been introduced to be better than the old and freeze-drying techniques (Maan et al., 2018). The microwave-assisted method is being used to remove the product waters through microwave heating technique. This procedure is not only cost and energy efficiency, but it enhances improved quality product and speedy operations (Maan et al., 2018).

\subsection{A. vera Concentrate}

When the temperature is below $50{ }^{\circ} \mathrm{C}$, A. vera juice can be concentrated for about $120 \mathrm{~s}$ under vacuum $(125 \mathrm{mmHg})$. The bioactive elements are very sensitive to pressure and temperature. Therefore, to avoid depletion of these bioactive compounds all the conditions must be carefully put into consideration (Ramachandra \& Rao, 2008). Then, its juice can now be concentrated into a suitable and desirable consistency for different food applications such as fruit juices, tea, jellies, jams, and squashes.

\subsection{PHARMACEUTICAL USES OF Aloe vera}

A lot of studies on the therapeutic uses of $A$. vera had increased the significant use of this plant in the pharmaceutical industries across the globe due to its medicinal constituents. Various types of preparation of therapeutic drugs have been produced from this plant in the form of tablets, capsule and ointment (Eshun \& He, 2004).

\subsection{Anti-inflammatory Activity}

A lot of studies on the in vivo and in vitro activity of $A$. vera gel had been reported to illustrate the anti-inflammatory activity of A. vera. A. vera contains an enzyme called peptidase bradykinase that reduces the bradykinins which produce pain (Kumar et al., 2010). A. vera produces great anti-inflammatory activities due to the chromone and anthraquinones. It had been reported in a patient with aphthous stomatitis that oral administration of $2 \%$ oral aloe gel in such patient decreased the wound size and severe pains alongside. Anti-inflammatory action of A. vera helps to decrease prostaglandin E2 production from arachidonic acid by preventing the cyclooxygenase pathway from taking place (Reynolds, 1999). Some reported results by Sahu et al. (2013) recommended that plant sterol in Aloe gel can provide anti-inflammatory effects. Moreover, there was component in the $A$. vera had been identified to be aspirin-like compounds which can contribute to antimicrobial and anti-inflammatory activities (Sahu et al., 2013). In addition, the uses of $A$. vera gel against colorectal mucosa had shown a strong anti-inflammatory potential (Xu et al., 2004).

\subsection{Wound Healing Effects}

Wound healing is described as a process tissues under the skin to regain themselves after injury. A. vera has a healing function that is related to a polysaccharide like mannose (glucomannan) (Bal et al., 2013). In this process, A. vera can be administered 
orally and topically on the site of an injury; a growth hormone called gibberellin attacked the growth factor fibroblast receptors, thereby causing the cell to proliferate by increasing the synthesis of secretion and collagen (Bal et al., 2013). A. vera contains some amino acids which are involved in the healing process of any wounds. Inorganic electrolytes present in the $A$. vera include zinc, iron, calcium, potassium, sodium, chromium, magnesium, and copper; these are the essential elements involved in the healing process of any wound (Sahu et al., 2013). Other studies reported that A. vera involves in stimulating a body to produce antibodies and synthesis of growth factors to begin the wound healing process. Many studies have reported the fast healing of wounds using A. vera treatment (Maan et al., 2018; Sahu et al., 2013).

\subsection{Anticancer Activity}

Glycoproteins and polysaccharides in A. vera make it a potent chemo preventive agent that is useful against various types of cancers (Reynolds, 1999). These agents stimulate the immune system to fight against cancer (Grace et al., 2008). The in vitro anticancer activity of $A$. vera against hepatocellular carcinoma (HepG2) cells, the obtained result indicated that the extract improved cytotoxicity against HepG2 cells I n a dosedependent manner (Shalabi et al., 2015).

\subsection{Anti-ulcer Activity}

Peptic ulcer is one of the major chronic gastrointestinal diseases that affect the world population today. A. vera gel is good at preventing and treatment of gastric ulcers through various mechanisms such as healing, anti-inflammatory properties, regulation of gastric secretions, and mucus stimulation (Maan et al., 2018). Suseela (2018) reported that $A$. vera possessed anti-ulcer property on rats induced with peptic ulcer inform of non-steroid inflammatory drug (NSAID). A. vera juice can also be used to relieve any form of gastrointestinal conditions such as the ulcerous cases. Nowadays, many people drink $A$. vera juice because it gives them an improved energy level and greater intestinal relief. Individuals suffering from colitis increased secretion of gastric acid and peptic acid, duodenal ulcer, irritable bowel syndrome, and indigestion have established comfort from these situations after ingesting the $A$. vera juice (Kumar et al., 2010).

\subsection{Antidiabetic Activity}

In any population of the world today, $A$. vera has been used as a traditional medication for Diabetes mellitus. A. vera gel is one of the popularly known antihyperglycemic substances used in the treatment of Type II diabetes. It reduces the blood sugar level by not altering the kidney or liver functions and normal lipid level of the blood (Rajasekaran et al., 2006). A. vera, among various plants, has low blood sugar trace elements including zinc, magnesium, and copper which enhances the insulin function of the plants. In the countries that are developing such as the Arab nations, A. vera has been used in treating diabetic persons (Ali, 2011). It has been reported that the metabolic effect of $A$. vera extracts on an over-weight patient diagnosed earlier with untreated Diabetes mellitus/prediabetes help lowering the insulin-resistance, fast body mass and body weight (Choi et al., 2013). It has also been established that an increase in metabolism resulted in reducing the blood sugars level. Rizk \& Sabri (2009) reported a reduction in fasting blood glucose, cholesterol and triglyceride in Type 2 diabetes patient using $A$. vera extracts It has been proposed that $A$. vera contain five phytosterols such as cycloartanol, 24-methyl-lenecycloartanol, 24-ethyl-lophenol, lophenol, and 24- 
methyl-lophenol which serves as an antihyperglycemic agent in mice induced with Type 2 diabetes (Tanaka et al., 2006).

\subsection{Antioxidant Activity}

The process of delaying autoxidation by preventing propagations of free radical through various mechanisms is called antioxidant. A. vera contains great numbers of antioxidant compounds which may help in increasing nutritional value and stability of food. It has been reported that the use of different model system showed different antioxidant properties of the extract of $A$. vera (Hęś et al., 2016). The cytotoxic and antioxidant activity were reported by López et al. (2017). A. vera possesses a great number of phenolic compounds (Maan et al., 2018). It is said to have a large content of aloe emodin (1,8-dihydroxyanthraquinone) derivatives and aloins (glycosides) which are involved in cathartics (Miladi \& Damak, 2008). Some rich source of antioxidants presents in $A$. vera includes such vitamin $\mathrm{C}$, vitamin A, $\alpha$-tocopherol, flavonoids, ascorbic acid, tannins, and carotenoids (Chauhan et al., 2014; Cuvas-Limón et al., 2016). Antioxidant potential of the extracts of $A$. vera (leaf and flower) had been reported by Lopez et al. (2013). A. vera has a dose-dependent antioxidant e ect, which is helpful in the treatment of various diseases (Hamman, 2008). Investigations of the antioxidant potential of a polysaccharide isolated from $A$. vera gel showed that it had a protective effect against dihydrochloride induced oxidative stress and cell death in kidney epithelial cells (Upadhyay, 2018).

\subsection{Antihyperlipidemic Effects}

A. vera gel is professed to have the ability to reduce blood lipid level, this is called antihyperlipidemic activity. A study had shown that the supplementation of $A$. vera gel proves a significant reduction of the blood lipid level in the non-insulin dependent diabetic patient in two groups. The reductions are as follow: low-density lipoprotein cholesterol (LDL-C) (135.9 to $126.8 \mathrm{mg} \%$ and 141.1 to $128.1 \mathrm{mg} \%$ ), very low density lipoprotein cholesterol (VLDL-C) (34.3 to $32.5 \mathrm{mg} \%$ and 35.4 to $32.7 \mathrm{mg} \%$ ), increased high density lipoprotein (HDL-C) (36.9 to $38.8 \mathrm{mg} \%$ and 34.9 to $37.2 \mathrm{mg} \%$ ), triglycerides (TG) (171.9 to $162.7 \mathrm{mg} \%$ and 177.4 to $163.8 \mathrm{mg} \%$ ), and total cholesterol (TC) (207.2 to $196.9 \mathrm{mg} \%$ and 211.5 to $198.1 \mathrm{mg} \%$ (Baldiet al., 2013).A. vera contains phytosterols such as lupeol, campesterol and sitosterol which possessed similar structure to cholesterol, they help in reducing the absorption of cholesterol from the small intestine in mixed micelles (Hamman, 2008).

\subsection{Antibacterial Activity}

A. vera as an antimicrobial efficacy was used for decontaminant of gutta-percha cones. The effectiveness of $A$. vera as an antimicrobial agent in decontaminating process was evaluated and determined using diffusion method. The result showed that after $48 \mathrm{~h}$ of incubation, there were zones of inhibition on the media plate which proves that $A$. vera is an effective decontaminant of gutta-percha cones (Hills et al., 2014; Kargaran et al., 2016). A. vera gel extract can shows maximum and effective antibacterial activity against common skin infections usually caused by gram-positive bacteria like Staphylococcus aureus and Staphylococcus epidermidis; and gram-negative organisms such as Escherichia coli, Klebsiella pneumonia, Pseudomonas vulgaris, Pseudomonas aeruginosa, and Pseudomonas mirabilis. Some of these causative organisms are resistant to broad-spectrum antibiotics like methicillin and vancomycin. This reveals the 
significant of $A$. vera gel as a natural product that can help in controlling antibiotics resistant pathogen which has been a great challenge to human health (Bashir et al., 2011; Udgire \& Pathade, 2014). Similar results were observed using A. vera juice to evaluate antimicrobial activity in human life (Kumar et al., 2017). Furthermore, high concentrations of $A$. vera gel showed better antimicrobial properties against oral pathogenic bacteria in oral-health treatment (Jain et al., 2016). Studies had shown that $A$. vera gel can be used as an antimicrobial edible coating for various kinds of fruits to maintain the food quality requirements and safety (Maan et al.,2018; Misir et al., 2014). Hence, A. vera gel can provide safety condition to food by preventing them from foodborne microbial spoilage.

\subsection{Antifungal Activity}

A. verai s all-round natural product with no side effects, it is used in the treatments of stubborn yeast and fungal infections. Fungi infections are the leading cause of mortality and morbidity in the world today. A report was proposed using a diffusion method, it was reported that about $1000 \mu \mathrm{g} / \mathrm{ml}$ concentrations of $A$. verae xtract inhibit the growth of Candida albicans effectively (Manipal et al., 2015). Another study was investigated using $A$. vera as an antifungal agent to inhibit the growths of Colletotrichum cococodes, Rhizoctonia solani and Fusarium oxysporun. Moreover, A. vera plants contain saponins, a soapy substance which serves as antiseptic and cleansing agents against fungi and yeast (Sahu et al., 2013). Another study affirmed that alcoholic A. vera leaf extracts can be used as a therapeutic agent to inhibit the growth of some selected fungal species that causes infection of the middle and external auditory canal of the ear such as Aspergillus sp. and Candida albicans (Saniasiaya et al., 2017).

\subsection{Activity on Genital Herpes}

Genital herpes is one of the popular sexual transmitted infections caused by Herpes simplex virus, it is identified as a red bump with painful fluid in the genital area. Genital herpes cannot be cured but can only be prevented by not allowing its symptoms to become an outbreak. Treatment for this disease requires self-care activity such as the use of $A$. vera supplements, eating habit and stress reduction. A. vera gel extract has been reported to have antiviral effects on Herpes simplex virus Type 1 . In an in vitro study, the results showed that about $0.2-5 \%$ of $A$. vera gel significantly inhibits the growth of Herpes Simplex Virus Type 1 in Vero cell line (Rezazadeh et al., 2016). In addition, hydrophilic cream containing $0.5 \%$ of $A$. vera extract had been reported used for treating genital herpes in men (Syed et al., 2009).

\subsection{Activity on HIV Infection}

HIV disease is caused by an RNA virus. There are two causative agents of acquired immunodeficiency syndrome namely: Human immunodeficiency virus Type 1 and 2 . About forty million of the world population are living with HIV infections. About $80 \%$ of people living with HIV are found in Sahara Africa (Olatunya et al., 2012). A. vera possesses a unique complex polysaccharide called glucomannan which is made up of mannose sugar (Sushen et al., 2017). The damaged tissues are repaired by this glucomannan by interacting with fibroblast to stimulate, activate their growth and replication (Olatunya et al., 2012). The extract of mannose, one of the sugars found in A. vera was used to treat human immunodeficiency virus Type 1 and the result showed $30 \%$ reduction in virus reproduction, suppressing the spreading of the virus and increasing in the chance of survival (Kumar et al., 2010). A. vera gel is an essential part 
for human immunodeficiency positive patients in a nutritional support program. Researchers had also discovered that $A$. vera can be used to stimulate T4 helper cells in immunosuppressed patients (Kumar et al., 2010). Moreover, the use of herbal drugs for the treatment of HIV infected patients was investigated due to lesser adverse side effect and inexpensive (Olatunya et al., 2012).

\subsection{Activity on Chronic Bronchial Asthmatic}

Storage of $A$. vera extract at $4{ }^{\circ} \mathrm{C}$ in the dark for a period of 3-10 days produces some active compounds (prostanoids) in the glycoprotein and polysaccharide fractions. These active compounds have shown e ectiveness against chronic bronchial asthmatics. However, the activity against asthma becomes ineffective if the patient has been previously administered with a steroid drug (Reynolds, 1999).

\subsection{Protection of Teeth and Gum}

A. vera is very useful in the area of dentistry because it is mostly used after the periodontal surgery to provide pain relief and quick recovery (Subramaniam et al., 2014). A. vera has a wide range of dental uses such includes application in gum tissues when they have been traumatized by sharp foods, toothpick or scratched by tooth brushdentifrice abrasion; it can be applied on the alpthous ulcer, cracks at the corners of the lips, and herpetic lesions. It is beneficial to people with denatures maladaptive, sore teeth and gum. It is used in the treatment of periodontal diseases called periodontitis and gingivitis by reducing inflammation, swelling and bleeding of the teeth. A. vera is used in producing mouthwashes which are affordable and effective antiplaque herbal agent substitute for chlorhexidine. A study had reported that sodium hypochlorite and chlorhexidine cytological were toxic to the periodontal ligament cells of human thereby retarding mitochondrial activity and protein synthesis causing detrimental of the vital tissue (Subramaniam et al., 2014).

\subsection{Laxative Agent}

A. vera gel composed of potent laxative called anthraquinones. It is locally used in the treatment of constipation. It helps to stimulate mucus secretion for improving intestinal peristalsis and water content. After oral administration of about $0.25 \mathrm{mg}$ of $A$. vera, the laxative effects take place between 6 to $12 \mathrm{~h}$ but sometimes more than $24 \mathrm{~h}$ before intestinal peristalsis takes place. There is no laxative activity in infants, therefore, nursing mothers are safe to take it (Maan et al., 2018; Sahu et al., 2013).

\subsection{Activity on the Stress}

A. vera juice plays an important role in protecting body machinery from oxidative stress and in smooth functioning of the cell during stress. It helps in minimizing physiological and biochemical changes in the body. A study had reported how A. vera moderately reduced physiobiological and morphological trait salt stress (Murillo-Amador et al., 2015).

\subsection{Cosmetic Usage}

\subsection{OTHER USES OF Aloe vera}

A. vera contains a special anti-ageing property which helps in maintaining fresh-looking healthy skin. Cosmetics are applied externally on the hair, eyes, lips, nails, and skin to enhance or change their beauty. A. vera composed about 20 amino acids and minerals such as sodium, magnesium, calcium, nitrogen, polysaccharides, vitamins, and others 
that made it a beautiful miraculous herbal plant (Sushen et al., 2017). The cosmetic property is its soothing, moisturizing, protective, and anti-inflammatory functions. In the seventies in the United States of America, it became very famous as a moisturizing component in cosmetic (Periasamy et al., 2014). Its moisturizing and penetrating effects help in stimulating cell growth and rejuvenating injured skin. A. vera gel gloves are used to reduced erythema, acne wrinkle and enhancing skin integrity. Furthermore, $A$. vera gel can be used to treat pimples and to make the skin moist during dry weather. Due to its antimicrobial activities, it used in the treatments of benign skin cyst, boils and fungi infection such as tinea (Periasamy et al., 2014; Qadir, 2009; Sahu et al., 2013; Yadav, 2017).

In addition, $A$. vera can be used in the treatment of baldness and alopecia (Basmatker et al., 2011). This is a process whereby hair is loss faster than their re-growth. A. vera consists of several ingredients that make it very helpful in treating hair loss. Hair loss is prevented because the $\mathrm{pH}$ value of $A$. vera is 6 and a weak acid that is very near to the normal skin $\mathrm{pH}$ value of 5 . Its $\mathrm{pH}$ value is used to improve the revitalizations of the hair bulb by enhancing the penetration of the ingredients and strengthening its re-growth. Moreover, A. vera is very useful in the treatment of onychitis. This is inflammation nerve endings of the nails. It serves as an analgesic agent by reducing pains observed around the nerve ending of the nails (Basmatker et al., 2011). Nowadays A. vera has become the most valuable dermatological extract used in the cosmetic industries throughout the world.

\subsection{Applications in Food Industries}

Recently, food industries across the world have shown high interest in the use of $A$. vera gel as a functional ingredient in food such as beverages, ice creams and drinks. Traditionally, $A$. vera is being used as an edible coating to increase food conservation and appearance. The coating can be in the form of polysaccharide, lipid and protein, it can be used as a combination or alone. They serve as an obstruction to oxygen and moisture from processing to the last stage for storage. Natural biocide property of $A$. vera is not only to prevent food from spoilage but, to enhance food safety. Another merit of an edible coating is that they are biodegradable to lower packaging waste, giving headway for new products. In Table 2, grapes, chitosan was effectively used to control storage graymold, reduce decaying and prolonged storage (Romanazzi et al., 2002). Summary of application of $A$. vera in food is outlined in Table 2.

Table 2: Summary of the applications of A. vera in food

\begin{tabular}{|c|c|c|c|}
\hline No & Food products & Applications & References \\
\hline 1 & 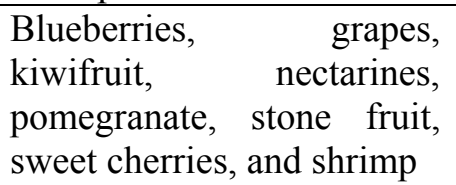 & Edible coating & $\begin{array}{l}\text { Chrysargyris et al. (2016); Mani et al. } \\
\text { (2017); Misir et al. (2014); Supapvanich et } \\
\text { al. (2016); Maan et al. (2018); Vargas et al. } \\
\text { (2008) }\end{array}$ \\
\hline 2 & $\begin{array}{l}\text { Mangoes, sweet cherries, } \\
\text { table grapes, beverages, } \\
\text { yogurts, and milks }\end{array}$ & $\begin{array}{l}\text { Therapeutic } \\
\text { agent }\end{array}$ & $\begin{array}{l}\text { Aloui and Khwaldia (2016); Elbandy et al. } \\
\text { (2014); Gharibi et al. (2015) }\end{array}$ \\
\hline 3 & $\begin{array}{l}\text { Ice cream, carbonated } \\
\text { beverages, squashes, lassi, } \\
\text { juices ready to be served, } \\
\text { and dahi, sweetened A. vera } \\
\text { juice }\end{array}$ & $\begin{array}{l}\text { Nutraceutical } \\
\text { and functional } \\
\text { agent }\end{array}$ & $\begin{array}{l}\text { Elbandy et al. (2014); Hussain et al. (2015); } \\
\text { Maan et al. (2018); Romano et al. (2012); } \\
\text { Upadhyay, (2018) }\end{array}$ \\
\hline
\end{tabular}




\subsection{COMPLICATIONS AND SAFETY PRECAUTIONS}

Several in vivo and in vitro assays had been carried out on A. vera latex; the analysis had shown some adverse side effect after consuming the chemical compounds present in the latex such as aloin, danthron, emodin, and aloe-emodin. These chemical components produced a carcinogenic, genotoxic and cytotoxic effect (Guo \& Mei, 2016). In salmonella assay, the genotoxicity of anthraquinone derivatives was observed but, the clinical importance of the experimental results was not clear enough. Another side effect of a laxative drug like rhubarb or Senna includes abdominal pain, cramps, meteorism, haemorrhoid congestion, flatulence, and urine coloration become reddish if the $\mathrm{pH}$ is alkaline or becomes orange if acidic (Mukherjee et al., 2013). Overdose can result in watery diarrhoea or bloody diarrhoea with mucus leading to haemorrhagic gastritis and electrolyte imbalance, vomiting and nephritis (Mukherjee et al., 2013). Also, it will lead to hypokalaemia that cause decreasing in colonic movement while sodium loss can end up in secondary hyperaldosteronism which lead to muscular weakness, steatorrhea, mental disturbance, kidney dysfunction, impaired autoimmune nervous system, and weight loss (Guo \& Mei, 2016; Mukherjee et al., 2013). However, A. vera laxative activity may be toxic and teratogenic during pregnancy (Minwuyelet et al., 2017).

Currently, aloin and anthraquinone in the A. vera gel had been reported to be the cause of colon cancers and tumour. Therefore, it has been recommended and mandated that cosmetic product produced from Aloe vera, aloin and anthraquinone content must not go beyond $50 \mathrm{ppm}$ to prevent photo-oxidative destruction to both DNA and RNA (Maan et al., 2018). Likewise, an allergic reaction may occur if A. vera is applied directly on a deep or open wound but, it is advisable to apply it safely on skin surface directly without injury (Christaki \& Florou-Paneri, 2016; Maan et al., 2018).

\subsection{CONCLUSION}

A. vera as an ethno-medicinal potential plant has been exploited globally for its therapeutic functions in the pharmaceutical, cosmetic and food industries. It is popular for its medicinal values. This miraculous and wonder plant has widely proven to be used in the treatments of many complications. The bioactive components in its succulent leaves are good for human health in immeasurable ways. However, the demand for the phytotherapeutic drugs across the globe has increased tremendously and there is need to search for new drugs that are herbal nature because most of the allopathic and synthetic drugs used these days usually developed antimicrobial resistant; this has been a major and global health challenge today in the health sector. Many trial studies had been reported on the bioactivity of this plant both in human and animals which had proven to be suitable for pharmaceutical, cosmetic and food applications. Although, some adverse side effect had been recorded in the laxative activity of this plant and safety precautions have been provided through many studies when taking this plant in form of laxative drugs or in the production of cosmetic and preservation of food. In addition, considering the increase in demand for natural products across the world and its economic importance, there is a need for more advanced technology in the vegetative cultivation of this plant and more studies are required to achieve this in a better and economical way. Additionally, there is a need for more health education on the use of herbal drugs to avoid its overdose complications. Conclusively, due to its positive effects that had been reported by various studies, $A$. vera can still be a cure or treatment for the infections. 


\section{REFERENCES}

Ahlawat, K. S. and Khatkar, B. S. (2011). Processing, food applications and safety of Aloe vera products: A review. Journal of Food Science and Technology,48(5), 525-533.

Ali Kamel Mohamed, E. (2011). Antidiabetic, antihypercholestermic and antioxidative effect of aloe vera gel extract in alloxan induced diabetic rats. Australian Journal of Basic and Applied Sciences,5(11), 1321-1327.

Aloui, H. and Khwaldia, K. (2016). Natural antimicrobial edible coatings for microbial safety and food quality enhancement. Comprehensive Reviews in Food Science and Food Safety,15(6), 1080-1103.

Arunkumar, S. and Muthuselvam, M. (2009). Analysis of phytochemical constituents and antimicrobial activities of Alpinia calcarata against clinical pathogens. World Journal of Agricultural Sciences,5(5), 572-576.

Bal, A., Ara, T., Deva, A. S. and Madan, J. (2013). Preparation and evalauation of novel Aloe vera gel beads. Journal of Global Bioscience,2(6), 206-216.

Baldi, A., Choudhary, N., \& Kumar, S. (2013). Nutraceuticals as therapeutic agents for holistic treatment of diabetes. International Journal of Green Pharmacy,7(4), 278.

Bashir, A., Saeed, B., Mujahid, T. Y. and Jehan, N. (2011). Comparative study of antimicrobial activities of Aloe vera extracts and antibiotics against isolates from skin infections. African Journal of Biotechnology,10(19), 3835-3840.

Basmatker, G., Jais, N. and Daud, F. (2011). Aloe vera: A valuable multifunctional cosmetic ingredient. International Journal of Medicinal and Aromatic Plants,1(3), 338-341.

Chauhan, S., Gupta, K. C. and Agrawal, M. (2014). Application of biodegradable Aloe vera gel to control post harvest decay and longer the shelf life of grapes. International Journal of Current Microbiology and Applied Sciences,3(3), 632642.

Choche, T., Shende, S. and Kadu, P. (2014). Extraction and identification of bioactive components from Aloe barbadensis. Journal of Pharmacognosy and Phytochemistry,2(1), 14-23.

Choi, H. C., Kim, S. J., Son, K. Y., Oh, B. J. and Cho, B. L. (2013). Metabolic effects of Aloe vera gel complex in obese prediabetes and early non-treated diabetic patients: Randomized controlled trial. Nutrition,29(9), 1110-1114.

Christaki, E. V. and Florou-Paneri, P. C. (2016). Aloe vera: A plant for many uses. Journal of Food, Agriculture and Environment,8(2), 245-249.

Chrysargyris, A., Nikou, A. and Tzortzakis, N. (2016). Effectiveness of Aloe vera gel coating for maintaining tomato fruit quality. New Zealand Journal of Crop and Horticultural Science,44(3), 203-217.

Cuvas-Limón, R., Julio, M., Carlos, C., Mario, C., Mussatto, S. and Ruth, B.-C. (2016). Aloe vera and probiotics: A new alternative to symbiotic functional foods. Annual Research \& Review in Biology,9(2), 1-11.

El-Shemy, H. A., Aboul-Soud, M. A., Nassr-Allah, A. A., Aboul-Enein, K. M., Kabash, A. and Yagi, A. (2010). Antitumor properties and modulation of antioxidant enzymes' activity by Aloe vera leaf active principles isolated via supercritical carbon dioxide extraction. Current Medicinal Chemistry,17(2), 129-138.

Elbandy, M. A., Elbandy, M. A., Abed, S. M., Gad, S. S. A. and Abdel-Fadeel, M. G. (2014). Aloe vera gel as a functional ingredient and natural preservative in mango nectar. World Journal of Dairy \& Food Sciences,9(2), 191-203.

Eshun, K. and He, Q. (2004). Aloe vera: A valuable ingredient for the food, 
pharmaceutical and cosmetic industries - A review. Critical Reviews in Food Science and Nutrition,44(2), 91-96.

Gharibi, D., Khosravi, M., Hosseini, Z., Boroun, F., Kolsum Barzegar, S. and Forughi Far, A. (2015). Antibacterial effects of Aloe vera extracts on some human and animal bacterial pathogens. Journal of Medical Microbiological and Infectious Diseases,3(2), 6-10.

Grace, O. M., Simmonds, M. S. J., Smith, G. F. and van Wyk, A. E. (2008). Therapeutic uses of aloe L. (Asphodelaceae) in southern Africa. Journal of Ethnopharmacology,119(3), 604-614.

Guo, X. and Mei, N. (2016). Aloe vera: A review of toxicity and adverse clinical effects. Journal of Environmental Science and Health - Part C Environmental Carcinogenesis and Ecotoxicology Reviews,34(2), 77-96.

Hamman, J. H. (2008). Composition and applications of Aloe vera leaf gel. Molecules,13(8), 1599-1616.

Hęś, M., Dziedzic, K., Le Thanh-Blicharz, J., Kmiecik, D. and Górecka, D. (2016). Antioxidant activity of true aloe (Aloe vera) extract in model systems. Nauka Przyroda Technologie,10(4), 1-12.

Hills, D., Author, C. and Morey, E. S. (2014). To evaluate the antimicrobial activity of herbal extracts and their efficacy in disinfecting gutta percha cones before obturation- An in vitro study. Journal of Medical Science and Clinical Research,2(10), 2676-2684.

Hussain, S. A., Panjagari, N. R., Singh, R. R. B. and Patil, G. R. (2015). Potential herbs and herbal nutraceuticals: Food applications and their interactions with food components. Critical Reviews in Food Science and Nutrition,55(1), 94-122.

Jain, S., Rathod, N., Nagi, R., Sur, J., Laheji, A., Gupta, N. and Prasad, S. (2016). Antibacterial effect of aloe vera gel against oral pathogens: An in-vitro study. Journal of Clinical and Diagnostic Research,10(11), ZC41-ZC44.

Kargaran, M., Moradabadi, A. R., Arjomandzadegan, M., Hosseini, H., Habibi, G., Tayeboon, M. and Akbari, A. (2016). Effects of the aqueous extract of Aloe vera on the morphological and physiological properties of E. coli. Iranian Red Crescent Medical Journal,19(2), e23896

Kumar, K. P. S., Bhowmik, D., Chiranjib and Biswajit. (2010). A potential herb and its medicinal importance. Journal of Chemical and Pharmaceutical Research,2(1), 21-29.

Kumar, S. (2017). Evaluating antimicrobial activity of aloe vera plant extract in human life. Biomedical Journal of Scientific \& Technical Research,1(7), 9-11.

Kumar, S. and Yadav, J. P. (2014). Ethnobotanical and pharmacological properties of Aloe vera: A review. Academic Journals,8(48), 1387-1398.

Lanka, S. (2018). A review on Aloe vera-The wonder medicinal plant. Journal of Drug Delivery and Therapeutics Open,8, 94-99.

Liu, P., Chen, D. and Shi, J. (2013). Chemical constituents, biological activity and agricultural cultivation of Aloe vera. Asian Journal of Chemistry,25(12), 64776485.

López, Z., Núñez-Jinez, G., Avalos-Navarro, G., Rivera, G., Salazar-Flores, J., Ramírez, J. A. and Knauth, P. (2017). Antioxidant and cytotoxicological effects of Aloe verafood supplements. Journal of Food Quality,2017, 1-10.

Maan, A. A., Nazir, A., Khan, M. K. I., Ahmad, T., Zia, R., Murid, M. and Abrar, M. (2018). The therapeutic properties and applications of Aloe vera: A review. Journal of Herbal Medicine,12, 1-10. 
Mani, A., Jain, N., Singh, A. K. and Sinha, M. (2017). Effects of Aloe vera edible coating on quality and postharvest physiology of Ber (Zizyphus mauritiana Lamk.) under ambient storage conditions. International Journal of Pure and Applied Bioscience,5(6), 43-53.

Manipal, S., Shireen, F. and Prabu, D. (2015). Anti-fungal activity of Aloe vera: In vitro studies. SRM Journal of Research in Dental Sciences,6(2), 92.

Miladi, S. and Damak, M. (2008). In vitro antioxidant activities of Aloe vera leaf skin extracts. Journal de La Société Chimique de Tunisie,10(7), 101-109.

Minwuyelet, T., Sewalem, M. and Gashe, M. (2017). Review on therapeutic uses of Aloe vera. Global Journal of Pharmacology,11(2), 14-20.

Misir, J., H. Brishti, F. and M. Hoque, M. (2014). Aloe vera gel as a novel edible coating for fresh fruits: A review. American Journal of Food Science and Technology,2(3), 93-97.

Molsaghi, M., Moieni, A. and Kahrizi, D. (2014). Efficient protocol for rapid Aloe vera micropropagation. Pharmaceutical Biology, 52(6), 735-739.

Mukherjee, P. K., Nema, N. K., Maity, N., Mukherjee, K. and Harwansh, R. K. (2013). Phytochemical and therapeutic profile of Aloe vera. Journal of Natural Remedies,14(1), 1-26.

Murillo-Amador, B., Nieto-Garibay, A., Troyo-Diéguez, E., García-Hernández, J. L., Hernández-Montiel, L. and Valdez-Cepeda, R. D. (2015). Moderate salt stress on the physiological and morphometric traits of Aloe vera L. Botanical Sciences,93(3), 1-10.

Olatunya, O. S., Olatunya, A. M., Anyabolu, H. C., Adejuyigbe, E. A. and Oyelami, O. A. (2012). Preliminary trial of Aloe vera gruel on HIV infection. The Journal of Alternative and Complementary Medicine,18(9), 850-853.

Ombito, J. O., Salano, E. N., Yegon, P. K., Ngetich, W. K., Mwangi, E. M., Koech, G. K. K. and Yegon, K. (2015). A review of the chemistry of some species of genus Aloe (Xanthorrhoeaceae family). Journal of Scientific and Innovative Research,4(41), 49-53.

Pandey, A. and Singh, S. (2016). Aloe vera: A systematic review of its industrial and ethno-medicinal efficacy. International Journal of Pharmaceutical Research \& Allied Sciences,5(1), 21-33.

Pansare, T. A., Sole, A. P., Shaikh, T. A. and Mahavidyalaya, A. A. (2018). Review on wound healing action of Kumari (Aloe vera L.) with special reference to Ayurvedic and mordern aspect. World Journal of Pharmacy and Pharmaceutical Sciences,7(5), 389-415.

Periasamy, G., Kassa, S., Sintayehu, B., Mebrahtom, G., Geremedhin, G. and Karim, A. (2014). Cosmetic Use of Aloe vera - A review. World Journal of Pharmacy and Pharmaceutical Sciences,3(5), 342-458.

Qadir, M. (2009). Medicinal and cosmetological importance of Aloe vera. International Journal of Natural Therapy,2, 20-26.

Rahimi-Dehgolan, R., Sarvestani, Z. T., Rezazadeh, S. A. and Dolatabadian, A. (2012). Morphological and physiological characters of Aloe vera subjected to saline water irrigation. Journal of Herbs, Spices and Medicinal Plants,18(3), 222-230.

Rajasekaran, S., Ravi, K., Sivagnanam, K. and Subramanian, S. (2006). Beneficial effects of Aloe vera leaf gel extract on lipid. Clinical and Experimental Pharmacology and Physiology,33, 232-237.

Raksha, B. (2014). Bioactive compounds and medicinal properties of Aloe vera L.: An update. Journal of Plant Sciences,2(3), 102. 
Ramachandra, C. T. and Srinivasa Rao, P. (2008). Processing of Aloe vera leaf gel: A review. American Journal of Agricultural and Biological Science. 3(2): 502-510.

Reynolds, T. and Dweck, A. C. (1999). Aloe vera leaf gel: A review update. Journal of Ethnopharmacology,68, 3-37.

Rezazadeh, F., Moshaverinia, M., Motamedifar, M. and Alyaseri, M. (2016). Assessment of anti HSV-1 activity of Aloe vera gel extract: An in vitro study. Journal of Dentistry Shiraz University of Medical Sciences,17(1), 49-54.

Rizk, S. M. and Sabri, N. A. (2009). Evaluation of clinical activity and safety of Daflon $500 \mathrm{mg}$ in Type 2 diabetic female patients. Saudi Pharmaceutical Journal,17(3), 199-207.

Romanazzi, G., Nigro, F., Ippolito, A., DiVenere, D. and Salerno, M. (2002). Effects of pre- and postharvest chitosan treatments to control storage grey mold of table grapes. Journal of Food Science,67(5), 1862-1867.

Romano, M., Vitaglione, P., Sellitto, S. and D'Argenio, G. (2012). Nutraceuticals for protection and healing of gastrointestinal mucosa. Current Medicinal Chemistry,19(1), 109-117.

Sahu, P. K., Giri, D. D., Singh, R., Pandey, P. and Gupta, S. (2013). Therapeutic and medicinal uses of Aloe vera: A review. Scientific Research,2013, 599-610.

Sahu, P. K., Giri, D. D., Singh, R., Pandey, P., Gupta, S., Shrivastava, A. K. and Pandey, K. D. (2013). Therapeutic and medicinal uses of Aloe vera: A review. Pharmacology \& Pharmacy,04(08), 599-610.

Saniasiaya, J., Salim, R., Mohamad, I. and Harun, A. (2017). Antifungal effect of Malaysian Aloe vera leaf extract on selected fungal species of pathogenic otomycosis species in in vitro culture medium. Oman Medical Journal,32(1), 4146.

Shalabi, M., Khilo, K., Zakaria, M. M., Elsebaei, M. G., Abdo, W. and Awadin, W. (2015). Anticancer activity of Aloe vera and Calligonum comosum extracts separetely on hepatocellular carcinoma cells. Asian Pacific Journal of Tropical Biomedicine,5(5), 375-381.

Subramaniam, T., Subramaniam, A., Chowdhery, A., Das, S. and Gill, M. (2014). Versatility of Aloe vera in dentistry-A review. IOSR Journal of Dental and Medical Sciences,13(10), 98-102.

Supapvanich, S., Mitrsang, P., Srinorkham, P., Boonyaritthongchai, P. and WongsAree, C. (2016). Effects of fresh Aloe vera gel coating on browning alleviation of fresh cut wax apple (Syzygium samarangenese) fruit. Journal of Food Science and Technology,53(6), 2844-2850.

Sushen, U., Unithan, C. R., Rajan, S., Chouhan, R., Sushma, C., Uddin, F. and Kowsalya, R. (2017). Aloe vera: A potential herb used as traditional medicine by tribal people of Kondagatu and Purudu of Karimnagar District. European Journal of Pharmaceutical and Medical Research,4(7), 820-831.

Ta, S., M, A., Ahmad, S. A., Holt, A., Ahmad, S. A. and Ahmad, S. (2009). Management of genital herpes in men with $0.5 \%$ Aloe vera extract in a hydrophilic cream: A placebo-controlled double-blind study. Journal of Dermatological Treatment,8(2), 99-102.

Tanaka, M., Misawa, E., Ito, Y., Habara, N., Nomaguchi, K., Yamada, M., Toida, T., Hayasawa, H., Takase, M., Inagaki, M. and Higuchi, R. (2006). Identification of five phytosterols from Aloe vera gel as anti-diabetic. Biological and Pharmaceutical Bulletin,29(7), 1418-1422.

Udgire, M. S. and Pathade, G. R. (2014). Antibacerial activity of Aloe vera against skin 
pathogens. American Journal of Ethnomedicine,1(3), 147-151.

Upadhyay, R. K. (2018). Nutraceutical, therapeutic and pharmaceutical potential of Aloe vera: A review. International Journal of Green Pharmacy,12(1), 51-70.

Vargas, M., Pastor, C., Chiralt, A., McClements, D. J. and González-Martínez, C. (2008). Recent advances in edible coatings for fresh and minimally processed fruits. Food Science and Nutrition,48(6), 496-511.

Xu, C. T., Meng, S. Y. and Pan, B. R. (2004). Drug therapy for ulcerative colitis. World Journal of Gastroenterology,10(16), 2311-2317.

Yadav, S. K. (2017). Medicinal and cosmetics uses of Aloe vera: A review. International Advance Research Journal in Science, Engineering and Technology,4(7), 126-127.

Zakia, S., Zahid, N. Y., Yaseen, M., Abbasi, N. A., Hafiz, A. A. and Mahmood, N. (2013). Standardization of micropropgation techniques for Aloe vera: A pharmaceutically important plant. Pakistan Journal of Pharmaceutical Sciences,26(6), 1083-1087. 